\title{
Research Progress on Pulmonary Arterial Hypertension and the Role of the Angiotensin Converting Enzyme 2-Angiotensin-(1-7)-Mas Axis in Pulmonary Arterial Hypertension
}

\author{
Feng Zhang ${ }^{1,2} \cdot$ Aidong Chen ${ }^{1,2} \cdot$ Yan Pan $^{1,2} \cdot$ Xingxing Wang ${ }^{1,2} \cdot \mathrm{Yu} \mathrm{Xu}^{1,2} \cdot$ Ankit A. Desai $^{3} \cdot$ Haiyang Tang $^{4,5} \cdot$ \\ Ying $\operatorname{Han}^{1,2}$ (D)
}

Accepted: 13 November 2020 / Published online: 4 January 2021

(C) Springer Science+Business Media, LLC, part of Springer Nature 2021

\begin{abstract}
Pulmonary arterial hypertension (PAH) is a progressive disease with a complex aetiology and high mortality. Functional and structural changes in the small pulmonary arteries lead to elevated pulmonary arterial pressure, resulting in right heart failure. The pathobiology of PAH is not fully understood, and novel treatment targets in PAH are desperately needed. The renin-angiotensin system is critical for maintaining homeostasis of the cardiovascular system. The system consists of the angiotensin converting enzyme (ACE)-angiotensin (Ang) II-angiotensin type 1 receptor $\left(\mathrm{AT}_{1} \mathrm{R}\right)$ axis and the ACE2-Ang-(1-7)-Mas receptor axis. The former, the ACE-Ang II-AT $\mathrm{A}_{1}$ axis, is involved in vasoconstrictive and hypertensive actions along with cardiac and vascular remodelling. The latter, the ACE2-Ang-(1-7)-Mas axis, generally mediates counterbalancing effects against those mediated by the ACE-Ang II-AT ${ }_{1}$ R axis. Based on established functions, the ACE2-Ang-(1-7)-Mas axis may represent a novel target for the treatment of PAH. This review focuses on recent advances in pulmonary circulation science and the role of the ACE2-Ang-(1-7)Mas axis in PAH.
\end{abstract}

Keywords Pulmonary arterial hypertension · Renin-angiotensin system $\cdot$ ACE-Ang II-AT ${ }_{1}$ R axis $\cdot$ ACE2-Ang-(1-7)-Mas axis

\section{Abbreviations}

ACE angiotensin converting enzyme

ACE2 angiotensin converting enzyme 2

Haiyang Tang

tanghy2008@yahoo.com

Ying Han

yhancn@njmu.edu.cn

1 Key Laboratory of Targeted Intervention of Cardiovascular Disease, Collaborative Innovation Center of Translational Medicine for Cardiovascular Disease, Nanjing Medical University, Nanjing 211166, Jiangsu, China

2 Department of Physiology, Nanjing Medical University, Nanjing 211166, Jiangsu, China

3 Department of Medicine, Indiana University, Indianapolis, IN, USA

4 College of Veterinary Medicine, Northwest A\&F University, Yangling 712100, Shaanxi, China

5 State Key Laboratory of Respiratory Disease, National Clinical Research Center for Respiratory Disease, Guangzhou Institute of Respiratory Health, The First Affiliated Hospital of Guangzhou Medical University, Guangzhou 510120, Guangdong, China

$\begin{array}{ll}\text { Ang-(1-7) } & \text { angiotensin-(1-7) } \\ \text { Ang II } & \text { angiotensin II } \\ \text { AT }_{1} \text { R } & \text { angiotensin II type 1 receptor } \\ \text { BMPR-II } & \text { bone morphogenetic protein receptor II } \\ \text { cGMP } & 3^{\prime}, 5^{\prime} \text {-cyclic guanosine monophosphate } \\ \text { ECs } & \text { endothelial cells } \\ \text { eNOS } & \text { endothelial nitric oxide synthase } \\ \text { ET-1 } & \text { endothelin-1 } \\ \text { EYA3 } & \text { eyes absent } 3 \\ \text { IL-6 } & \text { interleukin-6 } \\ \text { IL-8 } & \text { interleukin-8 } \\ \text { MCT } & \text { monocrotaline } \\ \text { NMDAR } & \text { N-methyl-D-aspartate receptor } \\ \text { NO } & \text { nitric oxide } \\ \text { PAH } & \text { pulmonary arterial hypertension } \\ \text { PASMCs } & \text { pulmonary artery smooth muscle cells } \\ \text { PH } & \text { pulmonary hypertension } \\ \text { PKG } & \text { protein kinase G } \\ \text { RAS } & \text { renin-angiotensin system } \\ \text { ROS } & \text { reactive oxygen species } \\ \text { sGC } & \text { soluble guanylate cyclase } \\ \text { SOD2 } & \text { superoxide dismutase 2 } \\ & \end{array}$




\section{Pulmonary Arterial Hypertension (PAH) Introduction}

PAH is a chronic disorder characterized by a progressive elevation in pulmonary vascular resistance, ultimately leading to right heart failure and death. PAH is defined as a pulmonary artery wedge pressure $\leq 15 \mathrm{mmHg}$, pulmonary vascular resistance $>3$ Wood units and an increase in mean pulmonary arterial pressure $\geq 20 \mathrm{mmHg}$ at rest $[1,2]$. PAH is classified as group 1 pulmonary hypertension $(\mathrm{PH})$ and has different forms [1]. These different aetiologies share common pathological features in PAH. Hallmark pathophysiologic changes of PAH include enhanced sustained vasoconstriction, obstructive vascular remodelling, in situ thrombosis and inflammation. Pharmacological agents currently approved for the treatment of PAH range from endothelin receptor antagonists, soluble guanylate cyclase stimulators, nitric oxide donors and phosphodiesterase inhibitors to prostacyclin analogues and prostacyclin receptor agonists. Although these treatments augment pulmonary vasodilation and improve symptoms, they do not significantly reverse vascular remodelling [3, 4]. This gap emphasizes the need to better understand the molecular mechanisms involved in the pathophysiology of PAH and the urgency to identify novel therapeutic strategies.

\section{Pathophysiology of PAH}

\section{Endothelial Dysfunction and Pulmonary Vasoconstriction}

The role of sustained vasoconstriction in the pathogenesis of PAH is well established. Endothelial dysfunctions are characterized by both reduced secretion of potent vasodilators, such as nitric oxide (NO) and prostacyclin, along with increased production of vasoconstrictors, such as endothelin-1 (ET-1), thromboxane and serotonin [4-7].

Vasodilatory effects of $\mathrm{NO}$ are mediated by soluble guanylate cyclase $(\mathrm{sGC}) / 3^{\prime}, 5^{\prime}$-cyclic guanosine monophosphate (cGMP) [8]. Research in patients [9] and animal experiments [10] have confirmed that NO deficiency is involved in the pathogenesis of PAH. Endothelial RhoA/Rho kinase signalling is responsible for the inhibition of both endothelial NO synthase (eNOS) expression and its activity in cultured endothelial cells (ECs) [11].

Prostacyclin stimulates the formation of cyclic adenosine monophosphate after binding to its receptors on smooth muscle cells (SMCs), leading to SMC relaxation. A deficiency of prostacyclin and an excess of thromboxane are found in patients with PAH and are associated with abnormal vasoconstriction [12].

ET-1 causes pulmonary artery SMC (PASMC) contraction by activating the Gq-protein-inositol triphosphate- $\mathrm{Ca}^{2+}$ pathway after binding to two receptors, $\mathrm{ET}_{\mathrm{A}}$ and $\mathrm{ET}_{\mathrm{B}}$, on SMCs [4].

\section{Pulmonary Vascular Remodelling}

Pulmonary vascular remodelling is manifested by the thickening of all three layers of the blood vessel wall - the intima, the media and the adventitia. Hypertrophy of the media and hyperproliferation of ECs and SMCs significantly drive the thickening of the vessels [13].

In PAH, dysfunction of ECs is manifested by increased secretion of vasoconstrictors, reduced secretion of vasodilators, increased proliferative capacity, a pro-inflammatory landscape and a smooth muscle-like mesenchymal phenotype transition [14]. Plexiform lesions are pathognomonic for PAH and are characterized by dysregulated proliferation and reduced apoptosis of ECs, leading to vascular obliteration. In fact, additional studies indicate that hypoxia-inducible factor$1 \alpha$ and hypoxia-inducible factor- $1 \beta$ are highly expressed in ECs derived from plexiform lesions during hypoxia and may contribute to the overproduction of mitogenic factors and their receptors, such as vascular endothelial growth factor $[15,16]$. More recently, increased hypoxia-inducible factor- $2 \alpha$ has also been reported to contribute to severe PAH by causing endothelial-to-mesenchymal transition [17].

Several lines of evidence suggest that increased activities of platelet-derived growth factor, epidermal growth factor, fibroblast growth factor and c-kit-receptor signalling pathways contribute to the excessive proliferation and migration of SMCs and ECs [18-21].

In addition to the role of ECs in promoting proliferation, ECs in PAH secrete increased levels of procoagulant factors and antifibrinolytic mediators. Failure of the thrombus in situ in the pulmonary circulation to dissolve over long periods is thought to contribute to vascular remodelling and fibrosis and eventually to increase pulmonary artery resistance [22].

Under pathological conditions, PASMCs can undergo phenotypic changes, including proliferation, migration and secretion, in response to bioactive agents [23]. Hyperplasia of PASMCs in the media layer of the pulmonary artery also leads to muscularization of previously non-muscularized arteries and an increase in the degree of muscularization of already muscularized pulmonary arteries [24]. Numerous studies have investigated the molecular mechanisms underlying the hyperproliferative phenotype of PASMCs. Imbalance between vasodilators and vasoconstrictors not only contributes to increased vasoconstriction, as mentioned before but also leads to PASMC proliferation. Prostacyclin inhibits PASMC proliferation and decreases platelet aggregation [25]. ET-1 may contribute to the abnormal proliferation of PASMCs in PAH by stimulating the mitogen-activated protein kinase family signalling pathway after binding to its receptors [26]. Recently, epigenetic factors were suggested to play a role in 
PAH. Several studies have shown evidence to support the role of microRNAs in the hyperproliferation of PASMCs. The expression of microRNA-21 was increased in human PASMCs exposed to hypoxia. Inhibition of microRNA-21 reduced hypoxia-induced cell proliferation and migration [27]. In contrast, the expression of microRNA-204 was decreased in human PAH and in rats with hypoxia- and monocrotaline (MCT)-induced PAH. Treatment with synthetic microRNA-204 in animals with PAH ameliorated pulmonary haemodynamics and vascular remodelling [28]. The DNA damage/poly(ADP-ribose) polymerase-1 signalling pathway may further mediate the role of microRNA-204 [29]. More recently, several studies have reported that ZIP12 [30], the glutamate-N-methyl-D-aspartate receptor (NMDAR) axis [31] and the Eyes Absent 3 (EYA3) tyrosine phosphatase may underlie hyperplasia of PASMCs [32]. Despite significant progress, the mechanisms underlying vascular remodelling in PAH remain unclear.

\section{Inflammation in PAH}

A significant number of studies have highlighted the contribution of inflammatory responses to the development and progression of PAH [33]. A study reported that patients with PAH have increased inflammatory cytokines and lipid peroxidation with decreased antioxidant capacity [34]. Experimental PAH models show that inflammation precedes pulmonary vascular remodelling and $\mathrm{PAH}$, and furthermore, suppression of the immune response prevents PAH development [35]. Additional animal work has revealed that high mobility group box 1 protein induces the release of proinflammatory cytokines, the maturation of dendritic cells and the proliferation as well as aggregation of PASMCs, all leading to the formation of PAH [36]. Previous studies have revealed that germline mutations in bone morphogenetic protein receptor II (BMPR-II) in the pulmonary endothelium contribute to enhanced vasoconstriction and vascular remodelling $[37,38]$. In fact, reductions of BMPR-II also lead to the elevated secretion of pro-inflammatory cytokines, increased vascular permeability and increased infiltration of leukocytes in response to inflammatory stimuli. These data suggest that BMPR-II may contribute to endothelial barrier function and act as an anti-inflammatory molecule; its loss may be a key mechanism responsible for the initiation of PAH [39].

In view of the above pathogenesis, the currently approved specific drugs for PAH target the NO pathway, prostacyclin pathway and endothelin pathway (Table 1) to restore endothelial-dependent vasodilation function [28]. While there have been many studies that have evaluated a myriad of molecular targets to restore endothelial-dependent vasodilation, the prognosis for PAH remains poor. The field has an urgent need to develop new therapeutic targets to reverse the progressive narrowing of the pulmonary vasculature, perivascular
Table 1 Summary of specific drugs approved for pulmonary arterial hypertension

\begin{tabular}{ll}
\hline Category & Drugs \\
\hline Guanylate cyclase stimulators & Riociguat \\
Phosphodiesterase type 5 inhibitors & Sildenafil \\
& Tadalafil \\
& Vardenafil \\
Prostacyclin analogues & Epoprostenol \\
& Iloprost \\
Prostacyclin receptor agonists & Treprostinil \\
Endothelin receptor antagonists & Selexipag \\
& Ambrisentan \\
& Bosentan \\
& Macitentan \\
\hline
\end{tabular}

inflammation and pathological cardiac remodelling with the goal of improving patient outcomes.

\section{The Role of the ACE2-Ang-(1-7)-Mas Axis in $\mathrm{PAH}$}

\section{ACE2-Ang-(1-7)-Mas Axis}

The renin-angiotensin system (RAS) plays an important role in maintaining cardiovascular homeostasis and the balance of water and electrolytes in mammals. Classically, renin secreted by juxtaglomerular cells catalyses angiotensinogen to Ang I, which is then cleaved by ACE into Ang II. It is believed that $\mathrm{AT}_{1} \mathrm{R}$ mediates most functions of Ang II in the system. Systemic RAS functions include regulating blood pressure, excreting sodium and diuresis, and regulating blood volume [40]. In addition to the endocrine RAS, all components of the RAS have been found in tissues such as the heart, blood vessels and kidneys. Local functions of RAS span regulating local vascular-bed blood flow, controlling stimulation responses locally, and participating in cell proliferation, differentiation and apoptosis [41]. More importantly, it is documented that the system consists of two antagonistic (i.e. against each other) and coordinated axes, the ACE-Ang II$\mathrm{AT}_{1} \mathrm{R}$ axis and the ACE2-Ang-(1-7)-Mas axis [42, 43].

The ACE2 protein was found by cloning technology and is a widely distributed enzyme found in the heart, lungs, kidneys, intestines, uterus and testis, among other tissues [44]. The ACE2 enzyme is a specific monocarboxypeptidase that differs from ACE in substrate specificity and function. ACE2 can hydrolyze one amino acid residue to transform Ang I into Ang-(1-9), which is further degraded to Ang-(1-7) under the action of ACE. ACE2 can also directly hydrolyze the eighth phenylalanine of Ang II to produce Ang-(1-7). Because ACE2 has the ability to hydrolyze Ang II at 400 times that of Ang I, Ang-(1-7) is considered its main by-product [45, 
46]. Ang-(1-7) is an active heptapeptide composed of aspartic acid, arginine, valine, tyrosine, isoleucine, histidine and proline, which is mainly distributed in blood vessels, the heart, kidneys and ovaries, among other organs. Mas is a specific $\mathrm{G}$ protein-coupled receptor encoded by the Mas proto-oncogene, and Ang-(1-7) is its endogenous ligand [47].

The ACE2-Ang-(1-7)-Mas axis has complex biological effects. It can promote the release of prostaglandin and $\mathrm{NO}$ by ECs through an Akt-dependent signalling pathway after Mas receptor binding, resulting in vasodilation as well as anti-proliferative, anti-inflammatory and anti-thrombotic effects [46, 48-51]. Our recent study on spontaneous hypertensive rats has also shown that Ang-(1-7)-Mas relaxes isolated pulmonary arteries through the NO-cGMP-protein kinase G (PKG) pathway [52]. Studies on hypertensive rats with thrombosis have found that decreased ACE2 activity is involved in increased thrombus formation in hypertensive rats [53], and treatment with Ang-(1-7) exerts an anti-thrombotic action by inducing the release of $\mathrm{NO}$ and prostacyclin from ECs [54]. In addition, it can elicit protective effects on infarcted hearts [55]. These data together suggest that the ACE2-Ang-(1-7)-Mas axis can negatively regulate blood pressure, inhibit myocardial remodelling, decrease the production of inflammatory factors and resist adverse effects of the ACE-Ang II-AT ${ }_{1} \mathrm{R}$ axis, which are all functions that may benefit PAH. In the following section, we will review recent research progress on the ACE2Ang-(1-7)-Mas axis in PAH.

\section{Beneficial Role of the ACE2-Ang-(1-7)-Mas Axis in PAH}

\section{The ACE2-Ang-(1-7)-Mas Axis Improves Endothelial-Dependent Vasodilation}

A number of studies have consistently reported an imbalance of ACE-Ang II-AT ${ }_{1}$ R axis and the ACE2-Ang-(1-7)-Mas axis in PAH. Several clinical studies confirmed reduced levels of ACE2 [56] or the activity of ACE2 [57] in serum in PAH. Furthermore, enhancement of ACE2 activity decreases the Ang II/Ang-(1-7) ratio and ameliorates abnormal pulmonary haemodynamics by reducing reactive oxygen species (ROS) via superoxide dismutase 2 (SOD2) and inhibiting inflammation in patients with PAH [57]. A recent clinical study reported that ACE2 activity and the concentration of Ang-(1-7) are reduced, while Ang II levels are increased in patients with PAH [58]. Studies on animal models with PAH suggest that reduced activity of the ACE2-Ang-(1-7)-Mas axis may be attributed to an unstable ACE2, which is due to decreased phosphorylation of Ser680 by AMP-activated protein kinase [59]. Inhibition of the ACE-Ang II-AT ${ }_{1} \mathrm{R}$ axis and stimulation of the ACE2-Ang-(1-7)-Mas axis have been shown to decrease pulmonary arterial pressure and to improve vascular remodelling by increasing the production of $\mathrm{NO}$ [60].
A study on rat models of MCT-induced PAH found that microvesicles derived from mesenchymal stem cells improve haemodynamics, inflammation scores, and pulmonary vascular and cardiac remodelling by upregulating the ACE2Ang-(1-7)-Mas axis and downregulating the ACE-Ang-II$\mathrm{AT}_{1} \mathrm{R}$ axis [61]. A further study showed that $\mathrm{ACE} 2$ activation ameliorates PAH by inducing phosphorylation of eNOS, leading to increased release of $\mathrm{NO}$ [62]. The above results support that the ACE2-Ang-(1-7)-Mas axis exerts beneficial effects on PAH by potentially improving endothelial function. A schematic diagram of the proposed mechanisms of the ACE2-Ang-(1-7)-Mas axis in ECs and PASMCs in PAH is shown in Fig. 1.

\section{ACE2-Ang-(1-7)-Mas Axis Inhibits Vascular and Cardiac Remodelling}

The ACE-Ang II-AT $\mathrm{T}_{1} \mathrm{R}$ axis also promotes vascular and cardiac remodelling. A previous study in a hypoxia-induced rat model of PH found that ACE activity is significantly increased in the right ventricle [63]. Furthermore, Ang II-induced cardiac fibroblast proliferation and collagen deposition through protein kinase $\mathrm{C} \delta$, and $\beta$ II-dependent inactivation of $\mathrm{p} 38$ may be an underlying mechanism of right ventricular fibrosis in PAH [64]. ACE-Ang II-AT ${ }_{1} \mathrm{R}$ axis-induced vascular and cardiac remodelling may involve multiple processes, including stimulating cardiomyocyte hypertrophy and fibrocyte proliferation, increasing the release of catecholamine from sympathetic nerve endings and secretion of endothelin. Other studies have shown that Ang II can lead to pathological remodelling characterized by calcium signalling dysfunction, overexpression of primitive genes, inactivation of glycogen synthetase kinase- $3 \beta$ and aggregation of activated nuclear transcription factors in $\mathrm{T}$ cells, resulting in cardiac hypertrophy. Ang-(1-7), in contrast, prevents Ang II-mediated pathological remodelling via the NO/cGMP signalling pathway [65].

Ang-(1-7) also inhibits platelet-derived growth factor- and Ang II-mediated proliferation of PASMCs. Ang-(1-7) also exhibits anti-angiogenic features and improves endothelial function after stent implantation [66]. Administration of Ang-(1-7) into wild-type mice reduces neointimal area and PASMC proliferation by reducing oxidative stress and the inflammatory response. However, the effect was less obvious in Mas-deficient mice than in wild-type mice [67]. In addition, recent animal work in PH models found that activation of ACE2 improves pulmonary arterial remodelling mediated by the Hippo signalling pathwayinduced apoptosis [68], while a Mas inhibitor blocks the protective effects of ACE2 on pulmonary arteries. In other animal work, an adeno-associated virus vector containing both a Tie2 promoter and hypoxia response elements was designed to target the Ang-(1-7) gene [called HTSFcAng(1-7)]. The expression and release of Ang-(1-7) in HTSFcAng(1-7)-transfected ECs 


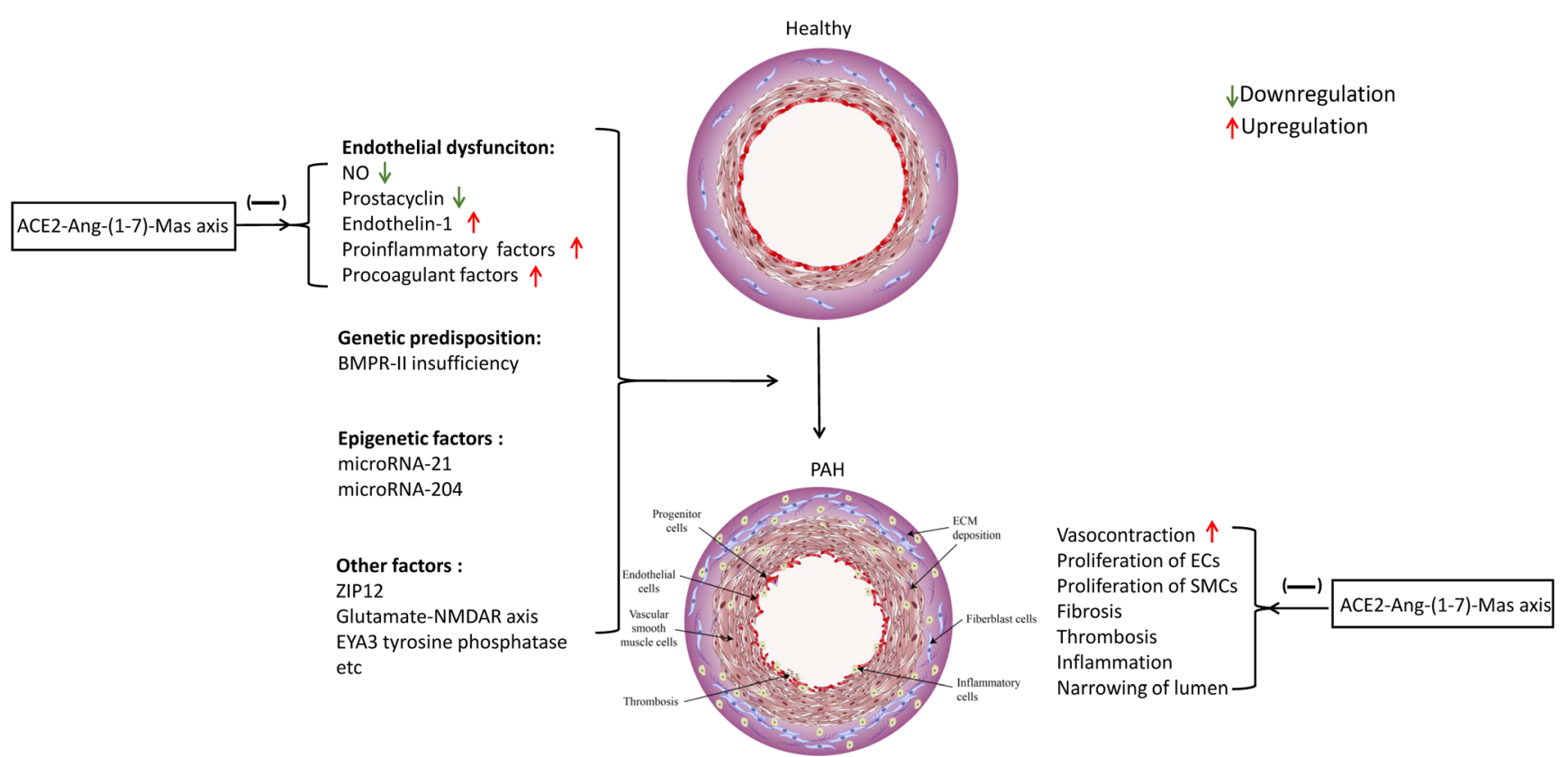

Fig. 1 A schematic diagram of the main mechanisms of the ACE2-Ang-(1-7)-Mas axis in ECs and PASMCs in PAH

were increased under both normoxic and hypoxic conditions, resulting in reduced hypoxia-induced proliferation of pulmonary arterial PASMCs with increased relaxation of pulmonary artery rings. In rats with hypoxia-induced PH, HTSFcAng(1-7) relieved pulmonary haemodynamics and pulmonary arterial remodelling [69]. In addition, treatment of MCT-induced PH rats with orally delivered ACE2 and Ang-(1-7) bioencapsulated within plant cells ameliorated right ventricular and pulmonary artery remodelling and attenuated total pulmonary resistance.
These beneficial effects of ACE2 and Ang-(1-7) in rodents involved alterations in Mas receptors, $\mathrm{AT}_{1}$ receptors, IL-1 $\beta$ and TGF- $\beta 1$ [70] (in Fig. 1).

The pathophysiologic mechanisms of right ventricular remodelling and dysfunction include calcium overload [71], oxidative stress injury and cardiomyocyte apoptosis [72, 73]. Ang-(1-7) supplementation can slow down the development of right ventricular dysfunction and improve the maximum rate of right ventricular pressure rise during the isovolumic systolic period [74,

Fig. 2 The general effects of the ACE2-Ang-(1-7)-Mas axis on vascular remodelling of the pulmonary artery in $\mathrm{PAH}$

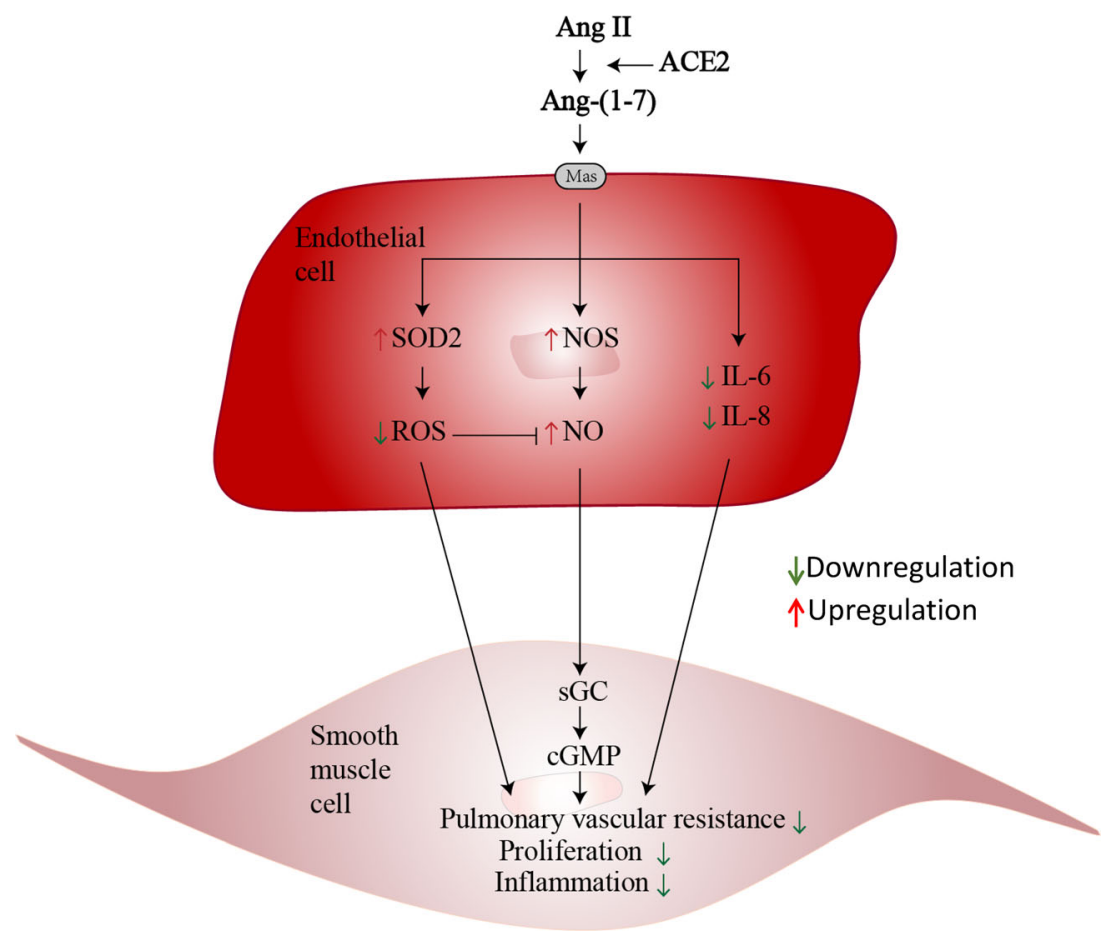


75]. Evidence was reported that Ang-(1-7) has protective effects on rat neonatal cardiomyocytes with hypoxia exposure in vitro, which is related to decreased tumour necrosis factor- $\alpha$ and interleukin (IL)-6 gene expression as well as increases in ACE2, bradykinin B2 receptor and IL-10 gene expression [76]. Overexpression of Ang-(1-7) can also improve cardiac function and alleviate left ventricular remodelling after myocardial infarction [76]. Further studies indicate that the beneficial effect of Ang-(1-7) on myocardial remodelling mediated by Ang II is related to the upregulation of the activity of dual-specificity phosphatase-1-mediated inhibition of the activity of mitogenactivated protein kinases [77].

The effects of the ACE2-Ang-(1-7)-Mas axis on vascular remodelling in PAH are shown in Fig. 2. Given that the currently approved treatments for PAH have little effect on improving cardiac function, the ACE2-Ang-(1-7)-Mas axis may hold significant promise.

\section{The ACE2-Ang-(1-7)-Mas Axis Inhibits the Inflammatory Response}

It has been reported that MCT increases the expression of inflammatory factors, such as IL-6 and IL-1 $\beta[78,79]$. Another study revealed that tumour necrosis factor $\alpha$ contributes to MCT-induced PH by suppressing pyruvate dehydrogenase [80]. The above studies suggest that overproduction of inflammatory factors is involved in the development of MCTinduced PH. In contrast, Ang-(1-7) overexpression reduces the expression of IL- $1 \beta$, IL- 6 , tumour necrosis factor- $\alpha$ and other pro-inflammatory factors involved in inflammation and increases the production of IL-10, an anti-inflammatory factor [75]. These data indicate that Ang-(1-7) can also improve PAH by inhibiting the pulmonary vascular inflammatory response.

\section{Conclusion}

PAH can be considered a chronic progressive disease with a complex aetiology and high morbidity and mortality. The ACE2-Ang-(1-7)-Mas axis represents a novel therapeutic pathway in PAH. Ang-(1-7) and ACE2 overexpression have both shown protective effects in PAH and right heart dysfunction. Therefore, further studies on the mechanisms of the ACE2-Ang-(1-7)-Mas axis can provide new potential drug targets in PAH.

Authors' Contributions All authors contributed to the work in this paper. Y.H. and H.T. conceived and designed the study. F.Z., A.D.C,Y.X., X.X.W. and Y.P. conducted the literature search and wrote parts of the paper. Y.H. and H.T. wrote the manuscript. A.A.D. provided intellectual suggestions and critically revised the article.
Funding This work was supported by the National Natural Science Foundation of China (grant numbers 31571168\&81470538), Qing Lan Project of Jiangsu Province of China and the Open Project of the State Key Laboratory of Respiratory Disease (grant number SKLRD-OP201911).

\section{Compliance with Ethical Standards}

Conflict of Interest The authors declare that they have no conflicts of interest.

Ethical Approval This article does not contain any studies with human participants or animals performed by any of the authors.

\section{References}

1. Galie N, Humbert M, Vachiery JL, Gibbs S, Lang I, Torbicki A, et al. $2015 \mathrm{ESC} / \mathrm{ERS}$ guidelines for the diagnosis and treatment of pulmonary hypertension: the joint task force for the diagnosis and treatment of pulmonary hypertension of the European Society of Cardiology (ESC) and the European Respiratory Society (ERS): endorsed by: Association for European Paediatric and Congenital Cardiology (AEPC), International Society for Heart and Lung Transplantation (ISHLT). Eur Respir J. 2015;46(4):903-75.

2. Condon DF, Nickel NP, Anderson R, Mirza S, de Jesus Perez VA. The 6th world symposium on pulmonary hypertension: what's old is new. F1000Res. 2019;8(F100 Faculty Rev):888.

3. Montani D, Chaumais MC, Guignabert C, Gunther S, Girerd B, Jais $\mathrm{X}$, et al. Targeted therapies in pulmonary arterial hypertension. Pharmacol Ther. 2014;141(2):172-91.

4. Humbert M, Lau EM, Montani D, Jais X, Sitbon O, Simonneau G. Advances in therapeutic interventions for patients with pulmonary arterial hypertension. Circulation. 2014;130(24):2189-208.

5. $\mathrm{Xu} \mathrm{W}$, Erzurum SC. Endothelial cell energy metabolism, proliferation, and apoptosis in pulmonary hypertension. Compr Physiol. 2011;1(1):357-72.

6. Mulvaney EP, Reid HM, Bialesova L, Bouchard A, Salvail D, Kinsella BT. NTP42, a novel antagonist of the thromboxane receptor, attenuates experimentally induced pulmonary arterial hypertension. BMC Pulm Med. 2020;20(1):85.

7. Delaney C, Sherlock L, Fisher S, Maltzahn J, Wright C, NozikGrayck E. Serotonin 2A receptor inhibition protects against the development of pulmonary hypertension and pulmonary vascular remodeling in neonatal mice. Am J Physiol Lung Cell Mol Physiol. 2018;314(5):L871-L81.

8. Rybalkin SD, Yan C, Bornfeldt KE, Beavo JA. Cyclic GMP phosphodiesterases and regulation of smooth muscle function. Circ Res. 2003;93(4):280-91.

9. Azeka E, Costa Auler JO Jr, Kajita L, Alliman AC, Franchini Ramires JA, Ebaid M. Effects of low doses of inhaled nitric oxide combined with oxygen for the evaluation of pulmonary vascular reactivity in patients with pulmonary hypertension. Pediatr Cardiol. 2002;23(1):20-6.

10. Archer S, Rich S. Primary pulmonary hypertension: a vascular biology and translational research "work in progress". Circulation. 2000;102(22):2781-91.

11. Takemoto M, Sun J, Hiroki J, Shimokawa H, Liao JK. Rho-kinase mediates hypoxia-induced downregulation of endothelial nitric oxide synthase. Circulation. 2002;106(1):57-62.

12. Christman BW, McPherson CD, Newman JH, King GA, Bernard GR, Groves BM, et al. An imbalance between the excretion of thromboxane and prostacyclin metabolites in pulmonary hypertension. N Engl J Med. 1992;327(2):70-5. 
13. Jeffery TK, Wanstall JC. Pulmonary vascular remodeling: a target for therapeutic intervention in pulmonary hypertension. Pharmacol Ther. 2001;92(1):1-20.

14. Humbert M, Guignabert C, Bonnet S, Dorfmuller P, Klinger JR, Nicolls MR, et al. Pathology and pathobiology of pulmonary hypertension: state of the art and research perspectives. Eur Respir J. 2019;53(1):1801887.

15. Tuder RM, Chacon M, Alger L, Wang J, Taraseviciene-Stewart L, Kasahara Y, et al. Expression of angiogenesis-related molecules in plexiform lesions in severe pulmonary hypertension: evidence for a process of disordered angiogenesis. J Pathol. 2001;195(3):367-74.

16. Veith C, Schermuly RT, Brandes RP, Weissmann N. Molecular mechanisms of hypoxia-inducible factor-induced pulmonary arterial smooth muscle cell alterations in pulmonary hypertension. $\mathrm{J}$ Physiol. 2016;594(5):1167-77.

17. Tang H, Babicheva A, McDermott KM, Gu Y, Ayon RJ, Song S, et al. Endothelial HIF-2alpha contributes to severe pulmonary hypertension due to endothelial-to-mesenchymal transition. Am J Physiol Lung Cell Mol Physiol. 2018;314(2):L256-L75.

18. Dai Y, Cheng R, Gao J, Li Y, Lou C, Li Y. Casticin inhibits PDGFinduced proliferation and migration of airway smooth muscle cells. Eur J Pharmacol. 2018;830:39-46.

19. Dahal BK, Cornitescu T, Tretyn A, Pullamsetti SS, Kosanovic D, Dumitrascu R, et al. Role of epidermal growth factor inhibition in experimental pulmonary hypertension. Am J Respir Crit Care Med. 2010;181(2):158-67.

20. Benisty JI, McLaughlin VV, Landzberg MJ, Rich JD, Newburger JW, Rich S, et al. Elevated basic fibroblast growth factor levels in patients with pulmonary arterial hypertension. Chest. 2004;126(4): 1255-61.

21. Elmasri H, Ghelfi E, Yu CW, Traphagen S, Cernadas M, Cao H, et al. Endothelial cell-fatty acid binding protein 4 promotes angiogenesis: role of stem cell factor/c-kit pathway. Angiogenesis. 2012;15(3):457-68.

22. Tuder RM, Cool CD, Geraci MW, Wang J, Abman SH, Wright L, et al. Prostacyclin synthase expression is decreased in lungs from patients with severe pulmonary hypertension. Am J Respir Crit Care Med. 1999;159(6):1925-32.

23. Sun HJ, Liu TY, Zhang F, Xiong XQ, Wang JJ, Chen Q, et al. Salusin-beta contributes to vascular remodeling associated with hypertension via promoting vascular smooth muscle cell proliferation and vascular fibrosis. Biochim Biophys Acta. 2015;1852(9):1709_ 18.

24. Pak O, Aldashev A, Welsh D, Peacock A. The effects of hypoxia on the cells of the pulmonary vasculature. Eur Respir J. 2007;30(2): 364-72.

25. Clapp LH, Finney P, Turcato S, Tran S, Rubin LJ, Tinker A. Differential effects of stable prostacyclin analogs on smooth muscle proliferation and cyclic AMP generation in human pulmonary artery. Am J Respir Cell Mol Biol. 2002;26(2):194-201.

26. Bouallegue A, Daou GB, Srivastava AK. Endothelin-1-induced signaling pathways in vascular smooth muscle cells. Curr Vasc Pharmacol. 2007;5(1):45-52.

27. Sarkar J, Gou D, Turaka P, Viktorova E, Ramchandran R, Raj JU. MicroRNA-21 plays a role in hypoxia-mediated pulmonary artery smooth muscle cell proliferation and migration. Am J Physiol Lung Cell Mol Physiol. 2010;299(6):L861-71.

28. Courboulin A, Paulin R, Giguere NJ, Saksouk N, Perreault T, Meloche J, et al. Role for miR-204 in human pulmonary arterial hypertension. J Exp Med. 2011;208(3):535-48.

29. Meloche J, Pflieger A, Vaillancourt M, Paulin R, Potus F, Zervopoulos S, et al. Role for DNA damage signaling in pulmonary arterial hypertension. Circulation. 2014;129(7):786-97.

30. Zhao L, Oliver E, Maratou K, Atanur SS, Dubois OD, Cotroneo E, et al. The zinc transporter ZIP12 regulates the pulmonary vascular response to chronic hypoxia. Nature. 2015;524(7565):356-60.
31. Dumas SJ, Bru-Mercier G, Courboulin A, Quatredeniers M, Rucker-Martin C, Antigny F, et al. NMDA-type glutamate receptor activation promotes vascular remodeling and pulmonary arterial hypertension. Circulation. 2018;137(22):2371-89.

32. Wang Y, Pandey RN, York AJ, Mallela J, Nichols WC, Hu YC, et al. The EYA3 tyrosine phosphatase activity promotes pulmonary vascular remodeling in pulmonary arterial hypertension. Nat Commun. 2019;10(1):4143.

33. Chan SY, Loscalzo J. Pathogenic mechanisms of pulmonary arterial hypertension. J Mol Cell Cardiol. 2008;44(1):14-30.

34. Reis GS, Augusto VS, Silveira AP, Jordao AA Jr, BaddiniMartinez J, Poli Neto O, et al. Oxidative-stress biomarkers in patients with pulmonary hypertension. Pulm Circ. 2013;3(4):856-61.

35. Price LC, Montani D, Tcherakian C, Dorfmuller P, Souza R, Gambaryan N, et al. Dexamethasone reverses monocrotalineinduced pulmonary arterial hypertension in rats. Eur Respir J. 2011;37(4):813-22

36. Sadamura-Takenaka $\mathrm{Y}$, Ito $\mathrm{T}$, Noma S, Oyama $\mathrm{Y}$, Yamada $\mathrm{S}$, Kawahara K, et al. HMGB1 promotes the development of pulmonary arterial hypertension in rats. PLoS One. 2014;9(7):e102482.

37. Soubrier F, Chung WK, Machado R, Grunig E, Aldred M, Geraci $\mathrm{M}$, et al. Genetics and genomics of pulmonary arterial hypertension. J Am Coll Cardiol. 2013;62(25 Suppl):D13-21.

38. Davies RJ, Morrell NW. Molecular mechanisms of pulmonary arterial hypertension: role of mutations in the bone morphogenetic protein type II receptor. Chest. 2008;134(6):1271-7.

39. Burton VJ, Ciuclan LI, Holmes AM, Rodman DM, Walker C, Budd DC. Bone morphogenetic protein receptor II regulates pulmonary artery endothelial cell barrier function. Blood. 2011;117(1): 333-41.

40. Karnik SS, Unal H, Kemp JR, Tirupula KC, Eguchi S, Vanderheyden PM, et al. International Union of Basic and Clinical Pharmacology. XCIX. Angiotensin receptors: interpreters of pathophysiological angiotensinergic stimuli [corrected]. Pharmacol Rev. 2015;67(4):754-819.

41. Forrester SJ, Booz GW, Sigmund CD, Coffman TM, Kawai T, Rizzo V, et al. Angiotensin II signal transduction: an update on mechanisms of physiology and pathophysiology. Physiol Rev. 2018;98(3):1627-738.

42. Donoghue M, Hsieh F, Baronas E, Godbout K, Gosselin M, Stagliano N, et al. A novel angiotensin-converting enzyme-related carboxypeptidase (ACE2) converts angiotensin I to angiotensin 19. Circ Res. 2000;87(5):E1-9.

43. Bader M. ACE2, angiotensin-(1-7), and mas: the other side of the coin. Pflugers Arch. 2013;465(1):79-85.

44. Gembardt F, Sterner-Kock A, Imboden H, Spalteholz M, Reibitz F, Schultheiss HP, et al. Organ-specific distribution of ACE2 mRNA and correlating peptidase activity in rodents. Peptides. 2005;26(7): 1270-7.

45. Santos RA, Ferreira AJ, Simoes ESAC. Recent advances in the angiotensin-converting enzyme 2-angiotensin(1-7)-mas axis. Exp Physiol. 2008;93(5):519-27.

46. Ocaranza MP, Jalil JE. Protective role of the ACE2/Ang-(1-9) Axis in cardiovascular remodeling. Int J Hypertens. 2012;2012:594361.

47. Clark WC, Dickson NM. Sustainability science: the emerging research program. Proc Natl Acad Sci U S A. 2003;100(14):8059-61.

48. Sampaio WO, Souza dos Santos RA, Faria-Silva R, da Mata Machado LT, Schiffrin EL, Touyz RM. Angiotensin-(1-7) through receptor mas mediates endothelial nitric oxide synthase activation via Akt-dependent pathways. Hypertension. 2007;49(1):185-92.

49. Zhang Y, Liu J, Luo JY, Tian XY, Cheang WS, Xu J, et al. Upregulation of angiotensin (1-7)-mediated signaling preserves endothelial function through reducing oxidative stress in diabetes. Antioxid Redox Signal. 2015;23(11):880-92.

50. Song B, Jin H, Yu X, Zhang Z, Yu H, Ye J, et al. Angiotensinconverting enzyme 2 attenuates oxidative stress and VSMC 
proliferation via the JAK2/STAT3/SOCS3 and profilin-1/MAPK signaling pathways. Regul Pept. 2013;185:44-51.

51. Fraga-Silva RA, Da Silva DG, Montecucco F, Mach F, Stergiopulos N, da Silva RF, et al. The angiotensin-converting enzyme 2/angiotensin-(1-7)/mas receptor axis: a potential target for treating thrombotic diseases. Thromb Haemost. 2012;108(6): 1089-96.

52. Zhang F, Tang H, Sun S, Luo Y, Ren X, Chen A, et al. Angiotensin(1-7) induced vascular relaxation in spontaneously hypertensive rats. Nitric Oxide. 2019;88:1-9.

53. Fraga-Silva RA, Sorg BS, Wankhede M, Dedeugd C, Jun JY, Baker MB, et al. ACE2 activation promotes antithrombotic activity. Mol Med. 2010;16(5-6):210-5.

54. Kucharewicz I, Pawlak R, Matys T, Pawlak D, Buczko W. Antithrombotic effect of captopril and losartan is mediated by angiotensin-(1-7). Hypertension. 2002;40(5):774-9.

55. Marques FD, Ferreira AJ, Sinisterra RD, Jacoby BA, Sousa FB, Caliari MV, et al. An oral formulation of angiotensin-(1-7) produces cardioprotective effects in infarcted and isoproterenoltreated rats. Hypertension. 2011;57(3):477-83.

56. Dai HL, Guo Y, Guang XF, Xiao ZC, Zhang M, Yin XL. The changes of serum angiotensin-converting enzyme 2 in patients with pulmonary arterial hypertension due to congenital heart disease. Cardiology. 2013;124(4):208-12.

57. Hemnes AR, Rathinasabapathy A, Austin EA, Brittain EL, Carrier EJ, Chen X, et al. A potential therapeutic role for angiotensinconverting enzyme 2 in human pulmonary arterial hypertension. Eur Respir J. 2018;51(6):1702638.

58. Sandoval J, Del Valle-Mondragon L, Masso F, Zayas N, Pulido T, Teijeiro $\mathrm{R}$ et al. Angiotensin converting enzyme 2 and angiotensin (1-7) axis in pulmonary arterial hypertension. Eur Respir J. 2020;56:1902416.

59. Zhang J, Dong J, Martin M, He M, Gongol B, Marin TL, et al. AMP-activated protein kinase phosphorylation of angiotensinconverting enzyme 2 in endothelium mitigates pulmonary hypertension. Am J Respir Crit Care Med. 2018;198(4):509-20.

60. Chang H, Chang CY, Lee HJ, Chou CY, Chou TC. Magnolol ameliorates pneumonectomy and monocrotaline-induced pulmonary arterial hypertension in rats through inhibition of angiotensin II and endothelin-1 expression. Phytomedicine. 2018;51:205-13.

61. Liu Z, Liu J, Xiao M, Wang J, Yao F, Zeng W, et al. Mesenchymal stem cell-derived microvesicles alleviate pulmonary arterial hypertension by regulating renin-angiotensin system. J Am Soc Hypertens. 2018;12(6):470-8.

62. Li G, Zhang H, Zhao L, Zhang Y, Yan D, Liu Y. Angiotensinconverting enzyme 2 activation ameliorates pulmonary endothelial dysfunction in rats with pulmonary arterial hypertension through mediating phosphorylation of endothelial nitric oxide synthase. J Am Soc Hypertens. 2017;11(12):842-52

63. Morrell NW, Danilov SM, Satyan KB, Morris KG, Stenmark KR. Right ventricular angiotensin converting enzyme activity and expression is increased during hypoxic pulmonary hypertension. Cardiovasc Res. 1997;34(2):393-403.

64. Chichger H, Vang A, O'Connell KA, Zhang P, Mende U, Harrington EO, et al. PKC delta and betall regulate angiotensin II-mediated fibrosis through p38: a mechanism of RV fibrosis in pulmonary hypertension. Am J Physiol Lung Cell Mol Physiol. 2015;308(8):L827-36.

65. Gomes ER, Lara AA, Almeida PW, Guimaraes D, Resende RR, Campagnole-Santos MJ, et al. Angiotensin-(1-7) prevents cardiomyocyte pathological remodeling through a nitric oxide/guanosine 3',5'-cyclic monophosphate-dependent pathway. Hypertension. 2010;55(1):153-60.

66. Langeveld B, van Gilst WH, Tio RA, Zijlstra F, Roks AJ. Angiotensin-(1-7) attenuates neointimal formation after stent implantation in the rat. Hypertension. 2005;45(1):138-41.
67. Ohshima K, Mogi M, Nakaoka H, Iwanami J, Min LJ, Kanno H, et al. Possible role of angiotensin-converting enzyme 2 and activation of angiotensin II type 2 receptor by angiotensin-(1-7) in improvement of vascular remodeling by angiotensin II type 1 receptor blockade. Hypertension. 2014;63(3):e53-9.

68. Yan D, Li G, Zhang Y, Liu Y. Angiotensin-converting enzyme 2 activation suppresses pulmonary vascular remodeling by inducing apoptosis through the hippo signaling pathway in rats with pulmonary arterial hypertension. Clin Exp Hypertens. 2019;41(6):58998.

69. Liu ML, Xing SJ, Liang XQ, Luo Y, Zhang B, Li ZC, et al. Reversal of hypoxic pulmonary hypertension by hypoxiainducible overexpression of angiotensin-(1-7) in pulmonary endothelial cells. Mol Therapy Methods Clin Develop. 2020;17:975-85.

70. Daniell H, Mangu V, Yakubov B, Park J, Habibi P, Shi Y, et al. Investigational new drug enabling angiotensin oral-delivery studies to attenuate pulmonary hypertension. Biomaterials. 2020;233: 119750.

71. Strauss B, Sassi Y, Bueno-Beti C, Ilkan Z, Raad N, Cacheux M, et al. Intra-tracheal gene delivery of aerosolized SERCA2a to the lung suppresses ventricular arrhythmias in a model of pulmonary arterial hypertension. J Mol Cell Cardiol. 2019;127:20-30.

72. Bogaard HJ, Abe K, Vonk Noordegraaf A, Voelkel NF. The right ventricle under pressure: cellular and molecular mechanisms of right-heart failure in pulmonary hypertension. Chest. 2009;135(3): 794-804.

73. Rondelet B, Dewachter C, Kerbaul F, Kang X, Fesler P, Brimioulle $\mathrm{S}$, et al. Prolonged overcirculation-induced pulmonary arterial hypertension as a cause of right ventricular failure. Eur Heart J. 2012;33(8):1017-26.

74. Hao PP, Yang JM, Zhang MX, Zhang K, Chen YG, Zhang C, et al. Angiotensin-(1-7) treatment mitigates right ventricular fibrosis as a distinctive feature of diabetic cardiomyopathy. Am J Physiol Heart Circ Physiol. 2015;308(9):H1007-19.

75. Shenoy V, Ferreira AJ, Qi Y, Fraga-Silva RA, Diez-Freire C, Dooies A, et al. The angiotensin-converting enzyme 2/angiogenesis-(1-7)/mas axis confers cardiopulmonary protection against lung fibrosis and pulmonary hypertension. Am J Respir Crit Care Med. 2010;182(8):1065-72.

76. Qi Y, Shenoy V, Wong F, Li H, Afzal A, Mocco J, et al. Lentivirusmediated overexpression of angiotensin-(1-7) attenuated ischaemia-induced cardiac pathophysiology. Exp Physiol. 2011;96(9):863-74.

77. McCollum LT, Gallagher PE, Ann TE. Angiotensin-(1-7) attenuates angiotensin II-induced cardiac remodeling associated with upregulation of dual-specificity phosphatase 1 . Am J Physiol Heart Circ Physiol. 2012;302(3):H801-10.

78. Bhargava A, Kumar A, Yuan N, Gewitz MH, Mathew R. Monocrotaline induces interleukin-6 mRNA expression in rat lungs. Heart Dis. 1999;1(3):126-32.

79. Voelkel NF, Tuder RM, Bridges J, Arend WP. Interleukin-1 receptor antagonist treatment reduces pulmonary hypertension generated in rats by monocrotaline. Am J Respir Cell Mol Biol. 1994;11(6): 664-75.

80. Sutendra G, Dromparis P, Bonnet S, Haromy A, McMurtry MS, Bleackley RC, et al. Pyruvate dehydrogenase inhibition by the inflammatory cytokine TNFalpha contributes to the pathogenesis of pulmonary arterial hypertension. J Mol Med (Berl). 2011;89(8): 771-83.

Publisher's Note Springer Nature remains neutral with regard to jurisdictional claims in published maps and institutional affiliations. 